\title{
LNG as fuel: demand opportunities and supply challenges in Austria
}

\author{
L. Simmer, S. Pfoser, G. Aschauer \& O. Schauer \\ University of Applied Sciences Upper Austria, Austria
}

\begin{abstract}
The transport sector is one of the most energy consuming and highest emissioncausing sectors. In order to counteract this circumstance, the European Commission has developed a European alternative fuels strategy. This strategy also encompasses the use of liquefied natural gas (LNG). In Austria, as well as in other landlocked European countries, LNG offers new market opportunities. However, there are lots of uncertainties and hurdles like no existing LNG infrastructure and very limited supply options to overcome. To make a significant contribution for the introduction of LNG as a fuel in Austria, the aim of this paper is on the one hand to identify pioneer customers to define interest and demand for LNG as a new fueling alternative and on the other hand to investigate different supply options and their economic performance. The analyses were conducted through desktop research, inquiries to LNG suppliers and transport companies as well as interviews with operators. First results of the supply analysis revealed LNG transportation costs, depending on the choice of transport mode (train, truck or inland vessel) and the reference terminal (Rotterdam or Zeebrugge). Findings of the demand analysis have highlighted that some interview partners already considered switching to LNG for very different purposes, whereby for other partners LNG is not an option. In fact, the missing LNG infrastructure and various hurdles in different supply options have been identified as the most apparent obstacle, which is impeding LNG usage.
\end{abstract}

Keywords: LNG, alternative fuel, supply chain, demand.

\section{Introduction}

With a share of $96 \%$, petroleum fuels are the predominant source of energy for transportation vehicles in Europe. Also in Austria the energy consumption of this sector is covered by $95 \%$ with petroleum products. In the period from 1990 to 
2010 , the transport sector recorded an increase in the final energy consumption of $76 \%$ and its share of total final energy consumption currently stands at 33\% (Umweltbundesamt [1]). According to current forecasts, energy demand in the transport sector will continue to grow. This high energy consumption in transport is not only about security of supply and the depletion of limited fossil fuel resources, but it is also of importance in regard to change and the health and quality of life in cities and rural areas (European Commission [2]). Traffic is a main source of fine particulate matter (PM 2.5) in cities, which can penetrate into lungs and cause serious health problems. In those Austrian provincial capitals where PM 2.5 is monitored, the recommended threshold of the World Health Organisation (WHO) of $10 \mu \mathrm{g} \mathrm{per} \mathrm{m}^{3}$ air has lately been exceeded considerably (VCÖ [3]). By using crude oil as primary energy source, road transport produces also significant amounts of greenhouse gases (GHGs). Therefore it is responsible for around a quarter of EU GHG emissions making it the second biggest emitting sector after the energy sector. Road transport alone contributes to about one-fifth of the EU's total emissions of carbon dioxide $\left(\mathrm{CO}_{2}\right)$, the main greenhouse gas and while emissions from other sectors are generally falling, those from transport have increased 36\% since 1990 (European Commission [4]). Emissions of GHGs are generally seen as a large problem since a temperature rise caused by the increasing concentrations of GHGs in the atmosphere is likely to influence global climate. Therefore the European Commission's Transport 2050 Strategy calls for breaking the oil dependence of transport and sets a target of $60 \%$ greenhouse gas emissions reduction from transport by 2050 (European Commission [5]). In order to reach these goals a big share of alternative fuels is required and therefore the transport sector has become a key area for projects to develop and demonstrate new technologies (European Commission [2]). In this context a drive to find alternative fuels has resulted in a variety of different fuels - few of which are commercially available in significant quantities. Natural gas is one of them which is widely available and can be renewable (through the production of biogas or bio-methane). Natural gas and bio-methane are also considered as main alternative fuels in the Commission Communication on a European alternative fuel strategy (COM (2013) 17) (European Commission [6]). Natural gas can be utilized as compressed natural gas $(\mathrm{CNG})$ or as liquefied natural gas (LNG). Compressed natural gas is already in use. 173 fueling stations for example exist in Austria, 133 in Switzerland, 910 in Germany, 974 in Italy, 55 in Czech Republic, 10 in Slovakia, 4 in Hungary and 3 in Slovenia. So in the EU more than 3,000 stations supply over one million natural gas vehicles (NGVA Europe [7]). However, LNG is not advanced in Austria, and the situation can be characterized as the often quoted chicken-and-egg problem. Investors do not put their money into building LNG infrastructure because there are not enough vehicles to use it. These, in turn, are not offered by manufacturers at competitive prices as there is not enough consumer demand. And consumers do not buy the vehicles because the infrastructure is not there. Another issue to overcome is how to supply Austria with LNG. For this, the purpose of this paper is on the one hand to identify potential pioneer consumers in the region of Upper Austria to outline the potential of LNG as vehicle fuel and on the other hand to analyse different supply options. An extensive literature research 
was carried out in a first step. Further research comprises the assessment of different supply chain scenarios and an initial demand survey in the region of Upper Austria.

\section{Results and discussion}

\subsection{Region analysis}

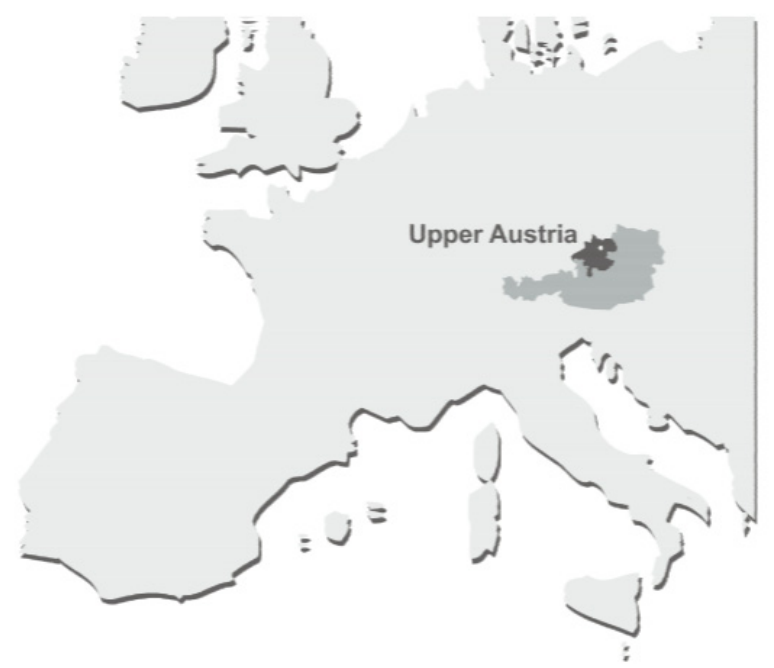

Figure 1: Location of Upper Austria, Egger et al. [8].

Upper Austria features substantial economic power and is the leading Austrian state in terms of exports, industry and technology. The most important economic sectors in Upper Austria are the manufacturing industry as well as construction businesses and the trade sector. In order to handle the considerable volume of cargo resulting from the expansive economic operations, there are lots of logistics service providers located in Upper Austria. Despite its importance as the major Austrian industrial site, Upper Austria was able to reduce GHG emissions in 2012 by $9 \%$ since 2005 . Thereby the transport sector recorded a decrease of $13.68 \%$ from 4.7 million tonnes to 4.1 million tonnes $\mathrm{CO}_{2}$ equivalents (Anschober [9]). However, since $1990 \mathrm{GHG}$ emissions from transport have risen from 2.6 million tonnes to 4.3 million tonnes in 2010. Thus, Upper Austria needs a decline of about 3.3 million tonnes until 2050 to attain environmental targets of the European Union (reducing GHG by at least 60\% until 2050 compared to 1990 in the transport sector) (Gratzer [10]).

LNG can help to reduce these emissions, because compared to diesel, LNG causes about $20 \%$ less $\mathrm{CO}_{2}, 80-90 \%$ less $\mathrm{NO}_{\mathrm{X}}$ and almost zero $\mathrm{PM}$ and $\mathrm{SO}_{\mathrm{X}}$ (Kumara et al. [11] and Baumann et al. [12]). With the use of liquefied bio- 
methane (LBG) $\mathrm{CO}_{2}$ emissions can even be further reduced. Moreover LBG could help to reach the committed target of Upper Austria to reduce the consumption of fossil fuels within the transportation sector by 2030 by $41 \%$ compared to 2005 levels (The Climate Group [13]).

\subsection{Demand}

In Upper Austria, there are a lot of companies with capacious vehicle fleets which could switch to LNG as a fuel. As it is not possible to interview all of them, a very diverse compilation of interview partners has been selected. Therefore in total ten interviews were conducted. Interview partners range from waste collecting companies and construction companies (because of their large truck fleet to distribute the materials they need for their construction projects) to logistic service providers, retailing companies and trucking companies with their own fleets.

The interviews confirmed the basic pursuit of sustainability which can be clearly perceived nowadays. Thus the vehicle pool of the interview partners is basically compliant to the latest exhaust emission standards. Moreover alternative fuels are an issue of importance to the Upper Austrian entrepreneurs, although diesel is definitely the most used fuel. Some companies cover parts of their fuel consumption with biodiesel. Most interview partners already evaluated the application of alternative fuels, but hardly any company uses them extensively for large parts of the fleet. They are rather in a stage of "trial", especially concerning natural gas as a fuel. This means that they purchased single $\mathrm{CNG}$ vehicles to gain some experience. Only one interview partner utter that alternative fuels are not very important for his company. The reason for this is that this company is operating in the field of construction logistics which means that they own a lot of special vehicles like cranes etc. where alternative fuels are not yet applicable.

Interestingly, LNG as a fuel was no completely new issue for some of the interviewed companies. In concrete terms, three interview partners have already examined the opportunity of introducing $\mathrm{LNG}$, respectively assessed the acquisition of LNG fuelled trucks. However, the response of six companies was that they have just heard of LNG (in some cases LNG was even completely unknown), but they never considered it as a feasible fuel option for their fleet. The main finding of the interviews is that interest for LNG as a fuel definitely exists in Upper Austria, but unfortunately there are still several barriers which are hampering this interest. This becomes clear since two of three companies which already extensively considered the introduction of LNG came to the conclusion that LNG is no viable fuelling possibility, at least at the moment. The remaining fleet owners (which have heard of LNG but didn't assess it in detail) were predominantly open-minded about LNG. Just one responded that LNG is no option at all for them because it is still a fossil fuel and they absolutely prefer renewable energies. This company however showed great interest in the opportunity of renewable and carbon-neutral LBG. Most of the other interviewed companies didn't specifically care about LBG. To sum up, if there is an additional environmental benefit, the companies would favor LBG, but economic viability is still the most important matter. 
Concerning the quantities requested by the potential customers, most companies would start with one to three LNG fuelled trucks. Just two companies could even imagine switching over to LNG for $100 \%$ of their fleet if the market conditions are appropriate and the technology is mature and proven. Therefore, sufficient supply structures and well-engineered LNG equipment are necessary. However, this is certainly not the case in Austria. Therefore, it can be assumed that the initial demand for LNG in Upper Austria would be limited to single pilot vehicles which will be operated by pioneer customers until the technology gains traction. If the pilot projects are successful, demand will gradually rise.

The typical two motives why the companies are interested in using LNG as a fuel for their fleet were economic and ecological advantages compared to other fuels. Nevertheless, the interview partners also stated some other reasons: (i) consciousness that mineral oil will run out sooner or later and therefore the need to ensure security of supply, (ii) to compensate drawbacks of CNG technology and to (iii) definite request of customer.

Another important part of the interviews was also to detect conditions which must be fulfilled in order to enable the introduction of LNG. The surveyed companies named a lot of requirements which could become severe challenges hindering LNG application in Upper Austria. The most basic condition is that LNG applications have to pay off; otherwise companies have no incentive to switch to LNG. As investment costs for LNG technology are still distinctly higher compared with traditional fuels, subsidies, funding or a tax exemption for LNG are necessary for establishing the technology. It is also essential that the obligatory infrastructure is provided and appropriate technology is available. Other issues mentioned were the fail to find a position where to locate the LNG tanks on specific trailers, concerns about the storage of LNG including the boil-off gas problems, the maintenance of LNG trucks, warranty issues with truck manufacturers for retrofitted trucks, the Austrian topography (alpine landscape) and legal issues. Above all, they see the task for the EU to provide harmonized, coherent regulations for all member states. A positive finding is that companies rarely worried about safety concerns so they seem to trust that LNG is a secure technology.

\subsection{Supply options}

Legal and technical issues as well as the spread of refueling infrastructure are only some issues a successful LNG implementation has to overcome. Another important question is how to supply the fuelling stations. Generally, there are two possibilities available: (i) to liquefy pipeline natural gas or bio-methane directly on site or (ii) to buy it at the LNG terminal.

The first option might be interesting for fuelling stations at far distance from terminals. Therefore great access to a natural gas pipeline is necessary. Another possibility is the liquefaction of bio-methane, which can be sourced from landfills, wastewater treatment plants and agriculture. Small scattered sources of natural gas could also be liquefied, because capacity and limited lifetime of these small wells cannot justify building of pipelines for bringing gas to places of potential consumption (Chrz and Emmer [15]). 
Anyway it has to be said that a liquefaction plant is the most expensive and most complicated part of the supply chain and liquefaction plant efficiency decreases markedly with plant size (Sinor [16]). Nonetheless, small liquefiers can be delivered in a modular design, readily installed and tested. A conducted study from Arteconi and Polonara [17] in Italy revealed that buying LNG at a terminal could be economically attractive up to terminal distances of 2,000 km, depending on LNG purchasing prices. The liquefaction on site is more interesting for those places farther from LNG terminals. For the economic feasibility of this option, a low natural gas pipeline price plays a central role. As the closest LNG Terminal is about $1,000 \mathrm{~km}$ away from Upper Austria, the first option was not further considered.

Regarding the second option, LNG can generally be transported from an inland terminal to landlocked countries by three possible means of transport, namely truck, train and inland waterway vessel. Thereby trucks are the most typically transportation mode. The transportation by truck to the users takes the form of LNG tank trucks (also called lorry) or ISO-containers. Tank trucks can vary greatly in their capacity, whereas 20 ISO-containers have a capacity of $20 \mathrm{~m}^{3}$ and 40 ISO-container of $43 \mathrm{~m}^{3}$ LNG (Chart Ferox [18]).

Terminals with truck loading opportunities in Europe are for example situated in Belgium, France, the Netherlands, Poland and Spain. The two closest terminals are the Gate terminal in the Netherlands (about $990 \mathrm{~km}$ away from the main city Linz - of Upper Austria) and the terminal in Zeebrugge, Belgium (about 1,030 km away) (GLE [19]). The other terminals were not considered as supply options due to large distances. Inquiries to transport companies revealed transportation prices from Belgium or the Netherlands between $11 € / \mathrm{MWh}$ and $15 € / \mathrm{MWh}$, whereby prices from the Gate terminal in Rotterdam are a little bit cheaper, due to the shorter distance. Thereby the companies offer LNG transportation with ISOcontainers. Due to rising market demand, the possibility of truck loading is currently assessed at the Panigaglia terminal in Italy. If this station will be realized in some years, Upper Austria could also obtain LNG from this terminal, which has only a distance of $830 \mathrm{~km}$.

The transportation of LNG by rail is rather an exemption in the world; only in Japan it is already very common (Japex [20]). As neither the Gate terminal in Rotterdam nor the terminal in Zeebrugge have a direct access to rail tracks, the LNG must first be transported by truck and then be reloaded to the train (GLE [19]). Therefore, nowadays just ISO-containers are used. Offered transportation prices for a single container transport lay at about $14 € / \mathrm{MWh}$, a whole block train would be cheaper.

Finally there is the theoretical option to transport LNG on inland waterway vessels. Theoretically, because no inland shipping LNG tanker exists nowadays, there are no possibilities (in Belgium or the Netherlands) to load a tanker ship and also because of legal issues. In principal, the International Carriage of Dangerous Goods by inland Waterways (ADN) regulates the transport of dangerous goods on inland waters. Due to missing listing of LNG as cargo within the cargo list Annex $\mathrm{C}$ of the ADN a transport in bulk by inland tankers is not allowed (Scholz [21]). Moreover if all these problems are solved, the bottleneck between Straubing and 
Vilshofen on the River Danube seriously hinders traffic, because it is too shallow for LNG cargo vessels (European Commission [22]). Another possible way in the future is the carriage of LNG from the other direction (Constantia, Galati or Ruse), but first these port cities will need a LNG terminal. Therefore an important ongoing EU-project called "LNG Masterplan for Rhine-Main-Danube" focuses on facilitating the transportation of LNG on the Rhine-Main-Danube axis and support feasibility studies, technical concepts and pilot deployments of terminals and vessels (Seitz [23]).

\section{Conclusion and outlook}

The European Commission's Transport 2050 Strategy calls for breaking the oil dependence of transport and sets a target of $60 \%$ greenhouse gas emissions reduction from transport by 2050 (European Commission [5]). In order to reach these goals a big share of alternative fuels is required. As LNG is an attractive alternative for many transportation applications, it will play an increasing role in the future. However, LNG is not advanced in Austria, and the situation is characterized as the often quoted chicken-and-egg problem. Pioneer customers and their potential demand as well as supply options and their economic performance are therefore important issues to overcome.

A basic pursuit of sustainability exists clearly along all interview partners and LNG was not a completely new issue for some of them. Therefore three interview partners already assessed the acquisition of LNG trucks and six companies have heard of LNG. Mentioned reasons why LNG could be interesting as a fuel were economic and ecological advantages, security of supply, compensate drawbacks of $\mathrm{CNG}$ technology and definite request of customers. In order to enable the introduction of LNG, following conditions must be fulfilled: LNG applications have to pay off in a given timeframe, obligatory infrastructure is provided and appropriate technology has to be available. Other topics which were addressed are: LNG tank position on specific trailer, storage and boil-off gas, the maintenance of LNG trucks, warranty issues with truck manufacturers for retrofitted trucks, the Austrian topography (alpine landscape) and legal issues. Concerning the quantities requested by the potential customers, most companies would start just with one to three LNG fuelled trucks. If these pilot projects are successful, demand could rise. In sum, interest for LNG as a fuel definitely exists in Upper Austria, but unfortunately there are still several barriers which are hampering this interest. Therefore potential pioneer companies should be encouraged to apply LNG by granting subsidies and ensure support from governmental and regulatory side. Moreover LNG suppliers could offer LNG contracts with a price linked to the price of diesel guaranteeing a fixed price advantage. These contracts can have a maturity of up to five years and hedge the price risk for the end users, which is a major advantage as it reduces the risk of an investment in LNG (PwC [24]).

A main weak point for LNG as fuel in Upper Austria is its distribution and particularly the supply process. In order to bring LNG either from the Gate terminal in the Netherlands or the terminal in Zeebrugge, Belgium to the end customer, the truck is the most common mode of transport. Inquiries to transport 
companies revealed transportation prices from Belgium or the Netherlands between $11 € / \mathrm{MWh}$ and $15 € / \mathrm{MWh}$, whereby prices from the Gate terminal in Rotterdam are a little bit cheaper, due to the shorter distance. Another opportunity is the transportation of LNG by rail, which is rather an exemption. As neither the Gate terminal in Rotterdam nor the terminal in Zeebrugge have a direct access to rail tracks, the LNG must first be transported by truck and then be reloaded to the train. Offered transportation prices for a single container transport lay at about 14 $€ / \mathrm{MWh}$, a whole block train would be cheaper. The transport of LNG with inland shipping tanker is just a theoretical option. Therefore it was not possible to get an offer for transportation prices. In sum, the transportation of LNG is no cheap business, especially due to expensive container rent and empty return transports.

\section{References}

[1] Umweltbundesamt, Energieeinsatz in Österreich, http://www.umweltbundesamt.at/umweltschutz/energie/energie austria/

[2] European Commission, Grünbuch - Die Sicherheit der Energieversorgung der Union, http://ec.europa.eu/energy/green-paper-energy-supply/doc/ green_paper_energy_supply_technical_de.pdf

[3] VCÖ, Health damage caused by fine particulate matter, http://www.vcoe.at/de/publikationen/vcoe-factsheets/details/items/ultrafeinstaub-macht-krank?print $=$ true $\&$ file $=$ tl files/vcoe/uploads/News/ VCOe-Factsheets/Factsheets/2013-02 VCOe-Factsheet Ultra-

Feinstaub.pdf

[4] European Commission, Reducing emissions from transport, http://ec.europa.eu/clima/policies/transport/index_en.htm

[5] European Commission, COM (2011) 112: A Roadmap for moving to a competitive low carbon economy in 2050; Brussels

[6] European Commission, COM (2013) 17 final: Clean Power for Transport: A European alternative fuels strategy; Brussels

[7] NGVA Europe, European NGV Statistics, http://www.ngvaeurope.eu/european-ngv-statistics

[8] Egger, C., Auinger, B. \& Öhlinger, C., Regional Report. The RES-H/C market in Upper Austria, http://www.res-h-policy.eu/RES-H_ Policy_Market-Report-Upper-AT_\%28D3\%29_engl_final.pdf

[9] Anschober, R., Klimaschutz: Oberösterreich ist auf Kurs! http://www.anschober.at/politik/presse/1976/--klimaschutz-oberoesterreich-ist-auf-kurs

[10] Gratzer, C., Presseunterlagen Infrastrukturen für nachhaltige Mobilität am Prüfstand, Daten und Zahlen der aktuellen VCÖ-Untersuchung, Linz 2011

[11] Kumara, S., Kwonb, H., Choib, K., Lima, W., Choa, J.H., Taka, K. \& Moon, I., LNG, An eco-friendly cryogenic fuel for sustainable development. Applied Energy, (88), pp. 4264-4273, 2011

[12] Baumann, K., Kruyt, B. \& Van der Burg, L., LNG-activities in DutchGerman cooperation. (MariTIM, LNG-Initiative Nordwest, WattenStart). 
Small Scale LNG Forum, MARIKO GmbH. Fleming Europe. Rotterdam, 2013

[13] The Climate Group, The State of Upper Austria, http://www.theclimategroup.org/who-we-are/our-members/the-state-ofupper-austria

[14] erdgas oö, Umweltinitiative Erdgas-Auto, http://erdgasooe.ooegw.at/de/ihre-vorteile/preisvorteile-und-foerderungenfuer-erdgas-fahrer.html

[15] Chrz, E. \& Emmer, C., LNG directly to customer stations, http://www.ivt.ntnu.no/ept/fag/tep4215/innhold/LNG\%20Conferences/200 7/fscommand/PO_12_Chrz_s.pdf

[16] Sinor, J.E., Comparison of CNG and LNG Technologies for Transportation Application, http://www.afdc.energy.gov/pdfs/2451.pdf

[17] Arteconi, A. \& Polonara, F., LNG as vehicle fuel and the problem of supply: The Italian case study. Energy Policy, (62), pp. 503-512, 2013

[18] Chart Ferox, ISO Containers, http://www.chart-ferox.com

[19] GLE, New LNG Services Inventory. http://www.gie.eu/index.php/mapsdata/gle-lng-services-inventory

[20] Japex, LNG Satellite System, https://www.japex.co.jp/english/business/japan/lng.html

[21] Scholz, B., Gas as fuel for ships - Rules and Regulations, http://www.mariko-leer.de/cms uploads/files/benjamin-scholz-gl.pdf

[22] European Commission, http://eur-lex.europa.eu/LexUriServ/LexUriServ. do? uri=COM:2002:0542:FIN:DE:PDF

[23] Seitz, M., http://www.lngmasterplan.eu/

[24] PwC, The economic impact of small scale LNG, http://www.nationaallngplatform.nl/wp-content/uploads/PwC-Economicimpact-of-small-scale-LNG_STC.pdf 